\title{
Correction to: Abstracts for MASCC/ISOO Annual Meeting 2021
}

\author{
Jocelyn White ${ }^{1}$ \\ Published online: 21 July 2021 \\ (c) Springer-Verlag GmbH Germany, part of Springer Nature 2021
}

\author{
Correction to: Supportive Care in Cancer (2021) 29 (Suppl 1):S1-S261 \\ https://doi.org/10.1007/s00520-021-06285-8
}

The list of authors and their details were incorrectly captured in the original manuscript. The corrected list is included below.

\section{CANCE-08 \\ LONGITUDINAL ASSESSMENT OF ADEQUACY OF PAIN MANAGEMENT AMONG STAGE III AND IV ORAL SQUAMOUS CELL CARCINOMA PATIENTS UNDERGOING SURGERY IN A TERTIARY CARE HOSPITAL IN SRI LANKA}

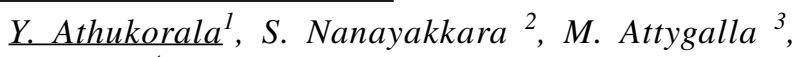
R.Pallegama ${ }^{4}$

${ }^{1}$ University of Peradeniya, Department of Nursing, Faculty of Allied Health Sciences, Peradeniya, Sri Lanka

${ }^{2}$ University of Peradeniya, Department of Anesthesiology and Critical Care, Faculty of Medicine, Peradeniya, Sri Lanka

${ }^{3}$ University of Peradeniya, Department of Oral and Maxillofacial Surgery, Faculty of Dental Sciences, Peradeniya, Sri Lanka

${ }^{4}$ University of Peradeniya, Department of Basic Sciences, Faculty of Dental Sciences, Peradeniya, Sri Lanka

Athukorala, Y. - CANCE-08 should be included in the author index

The online version of the original article can be found at https:// doi.org/10.1007/s00520-021-06285-8

Jocelyn White

jwhite@mascc.org

1 Multinational Association of Supportive Care in Cancer, 412-16 Industrial Parkway South, Aurora, ON L4G 0R1, Canada

\section{ANTIE-12}

LOW DOSE OLANZAPINE COMBINED WITH DOUBLET THERAPY FOR THE PREVENTION OF CARBOPLATIN-INDUCED NAUSEA AND VOMITING IN PATIENTS WITH THORACIC MALIGNANCIES

C. Hirose $^{1}$, H. Iihara $^{1}$, M. Shimokawa ${ }^{2}$, Y.Fujita $^{3}, S$. Ikemura $^{4}$, C. Sakai ${ }^{5}$, M. Kotake ${ }^{6}$, N. Funaguchi ${ }^{7}$, H. Imai ${ }^{6}$, J. Hakamata ${ }^{8}$, K. Minato ${ }^{6}$, T. Arai ${ }^{3}$, H. Kawazoe ${ }^{9}$, A. Suzuki $^{1}$, Y. Ohno ${ }^{5}$, H. Okura $^{5}$

${ }^{1}$ Gifu University Hospital, Department of Pharmacy, Gifu, Japan

${ }^{2}$ Clinical Research Institute, National Hospital Organization Kyushu Cancer Center, Cancer Biostatistics Laboratory, Fukuoka, Japan

${ }^{3}$ Gunma Prefectural Cancer Center, Division of Pharmacy, Gunma, Japan

${ }^{4}$ Keio University, School of Medicine, Division of Pulmonary Medicine, Department of Medicine, Tokyo, Japan

${ }^{5}$ Gifu University Graduate School of Medicine, Department of Cardiology and Respiratory Medicine, Gifu, Japan

${ }^{6}$ Gunma Prefectural Cancer Center, Division of Respiratory Medicine, Gunma, Japan

${ }^{7}$ Asahi University Hospital, Department of Respirology, Gifu, Japan

${ }^{8}$ Keio University Hospital, Department of Pharmacy, Tokyo, Japan

${ }^{9}$ Keio University Faculty of Pharmacy, Division of Pharmaceutical Care Sciences, Center for Social Pharmacy and Pharmaceutical Care Sciences, Tokyo, Japan 


\section{ANTIE-13}

EVALUATING OLANZAPINE 5 MG AND STANDARD TRIPLET THERAPY FOR THE PREVENTION OF CARBOPLATIN-INDUCED NAUSEA AND VOMITING IN GYNECOLOGIC CANCER PATIENTS

The list of authors and their details were incorrectly captured in the original manuscript. The corrected list is included below.

S. Yamamoto $^{1}$, H. Iihara ${ }^{1}$, M. Shimokawa ${ }^{2}$, Y. Hayasaki ${ }^{3}$, Y. Fujita ${ }^{4}$, M. Abe ${ }^{5}$, M. Takenaka ${ }^{3}$, T. Arai ${ }^{4}$, M. Sakurai ${ }^{6}$, M. Mori $^{3}$, K. Nakamura ${ }^{7}$, N. Kado ${ }^{5}$, S. Murase ${ }^{3}$, R. Shimaoka ${ }^{3}$, A. Suzuki ${ }^{1}$, K. Morishige ${ }^{3}$

${ }^{1}$ Gifu University Hospital, Department of Pharmacy, Gifu, Japan

${ }^{2}$ National Hospital Organization Kyusyu Cancer Center, Cancer Biostatistics Laboratory, Fukuoka, Japan

${ }^{3}$ Gifu University Graduate School of Medicine, Department of Obstetrics and Gynecology, Gifu, Japan

${ }^{4}$ Gunma Prefectural Cancer Center, Division of Pharmacy, Gunma, Japan

${ }^{5}$ Shizuoka Cancer Center Hospital, Division of Gynecology, Shizuoka, Japan

${ }^{6}$ Shizuoka Cancer Center Hospital, Department of Pharmacy, Shizuoka, Japan

${ }^{7}$ Gunma Prefectural Cancer Center, Department of Gynecology, Gunma, Japan

\section{ORALC-17}

\section{ORAL HEALTH IN PATIENTS PLANNED} FOR HEMATOPOIETIC STEM CELL TRANSPLANTATION

K. Skallsjö̈ ${ }^{1}$, I. von Bültzingslöwen ${ }^{2}$, B. Hasséus ${ }^{1}, J$. Johansson $^{3}$, M. Huysmans ${ }^{4}$, J. Raber-Durlacher ${ }^{5}$, N. Blijlevens $^{6}$, A. Laheij ${ }^{7}$, S. van Leeuwen ${ }^{8}$, F. Rozema ${ }^{9}$, A. Hovan ${ }^{10}$, K. Garming Legert ${ }^{11}$, H. Nguyen ${ }^{12}$, P. Turk ${ }^{12}$, M. Brennan $^{13}$
${ }^{1}$ Institute of Odontology, the Sahlgrenska Academy, Gothenburg, Sweden, Department of Oral Medicine and Pathology, Gothenburg, Sweden

${ }^{2}$ Institute of Odontology, the Sahlgrenska Academy, Department of Oral Microbiology and Immunology, Gothenburg, Sweden

${ }^{3}$ Sahlgrenska University Hospital, Department of Hematology and Coagulation, Gothenburg, Sweden

${ }^{4}$ Radboud University Medical Center, Department of Dentistry, Nijmegen, Netherlands

${ }^{5}$ Academic Centre for Dentistry Amsterdam, Department of Oral Medicine, Amsterdam, Netherlands

${ }^{6}$ Radboud University Medical Center, Department of Hematology, Nijmegen, Netherlands

${ }^{7}$ Academic Centre for Dentistry Amsterdam, Department of Oral Medicine, Amsterdam, Netherlands

${ }^{8}$ Radboud University Medical Center, Department of Dentistry, Nijmegen, Netherlands

${ }^{9}$ Academic Centre for Dentistry Amsterdam, Department of Oral Medicine, Amsterdam, Netherlands

${ }^{10}$ BC Cancer, Oral Oncology and Dentistry, Vancouver, Canada

${ }^{11}$ Karolinska Institute, Department of Dental Medicine, Stockholm, Sweden

${ }^{12}$ Atrium Health, Center for Outcomes Research and Evaluation, Charlotte, NC, United States

${ }^{13}$ Atrium Health, Department of Oral Medicine, Charlotte, NC, United States

Publisher's Note Springer Nature remains neutral with regard to jurisdictional claims in published maps and institutional affiliations. 